\title{
ESTUDIO DEL PATRIMONIO A TRAVÉS DEL DIBUJO: HIPÓTESIS VISUAL SOBRE LAS IMÁGENES DE LOS TEMPLETES DE LA GALERÍA EXTERIOR EN EL PEINADOR DE LA REINA DE LA ALHAMBRA
}

\author{
DRAWING-BASED HERITAGE ANALYSIS: VISUAL \\ HYPOTHESIS ABOUT THE SHRINES PAINTINGS OF \\ THE EXTERNAL GALLERY IN THE PEINADOR DE LA \\ REINA (QUEEN'S DRESSING ROOM) OF THE \\ ALHAMBRA
}

\author{
María Isabel Puerto Fernández \\ (Universidad de Granada, España) \\ maisapufe@gmail.com
}

Resumen: La galería exterior del Peinador de la Reina de la Alhambra, encontrada en la parte superior de la Torre Abu-l-Hayyay, muestra una decoración mural al fresco de estilo renacentista italiano, con un total de cuatro templetes entre composición grutesca: dos en la pared Oeste y dos en la pared Este. Pintados por Julio de Aquiles y Alexander Mayner, en estos templetes quedan representadas las figuras identificadas como Minerva, Júpiter ${ }^{1}$, Abundancia y Fuego Sagrado. El paso del tiempo, entre otros factores, ha ocasionado la desaparición parcial de las pinturas, siendo el objetivo de este artículo mostrar el estudio en torno a estos templetes, con un proceso de reconstrucción por medio del dibujo para llegar a una hipótesis visual que ayude a comprender cómo pudieron haber sido estas representaciones en su estado original.

\footnotetext{
${ }^{1}$ Para la descripción de las pinturas del Peinador de la Reina, por tratarse de un espacio dedicado al César Carlos V, y por el contexto renacentista y humanista en el que se encuentran, la alusión a los dioses clásicos se hará desde el punto de vista de la mitología romana.
} 
Palabras Clave: Alhambra; Peinador de la Reina; Dibujo de templetes; Julio Aquiles; Alexander Mayner.

Abstract: The external gallery in the Peinador de la Reina (Queen's Dressing Room²) of the Alhambra, it was built at the top of the Tower Abu-1-Hayyay. It presents a fresco mural decoration of Italian Renaissance style, with a total of four Shrines between grotto motifs composition: two on the West wall and two on the East wall. Painted by Julio de Aquiles and Alexander Mayner, in these Shrines are represented the figures identified as Minerva, Jupiter, Abundance and Sacred Flame. The passing of time and other factors, explain the state of disrepair in which part of the frescoes in this room are. Thus, the present article discusses the study carried out around the Shrines, and the process of reconstruction through drawing with a view to reaching a visual hypothesis that can help us to understand what these figures may have looked like in their original state.

Keywords: Alhambra; Peinador de la Reina; Drawings of Shrines; Julio Aquiles; Alexander Mayner.

\section{Introducción}

El Peinador de la Reina ${ }^{3}$ es un conjunto de estancias encontradas en la parte superior de la Torre de Abu-1-Hayyay de la Alhambra ${ }^{4}$ en Granada, que fueron reformadas en época cristiana tras la venida del Emperador Carlos V en 1526 a la ciudad, quien prefirió acomodar el palacio nazarí a las costumbres cristianas y gustos renacentistas. Así se muestra toda la iconografía representada en el Tocador de la Reina, especialmente en el Mirador, donde los frescos de la galería exterior muestran elementos propios de la

\footnotetext{
${ }^{2}$ O también llamado Queen's Robing Room.

${ }^{3}$ Conocido también con los nombres de: "Tocador de la Reina" (Andros, 1860, p. 99; Angulo, 1954, p. 227; 2010, p. 42; Bascle, 1872; Bermúdez, 1971, p. 2; Cavanah, 1987, p. 16; E. Rosenthal, 1988, pp. 15, 47,48; Gallego, 1996, pp. 102, 109; Gómez-Moreno González, 1873a; 1873b; 1888, pp. 138, 147; Gómez-Moreno Martínez, 1983, p. 222; Gómez-Moreno Calera, 2007b, pp. 42, 43, 45; Heredia, 2005, p. 137; Irving, 2001, p 35; Lafuente, 1843, pp. 160, 163; López, 1985, pp. 294, 385; 2000, p. 109; Martínez, 1997, p. 22; Martínez, 2019, p. 7; Moreno, 1993, p. 171; Pi Margall, 1981, p. 526; Ramos, 1972, p. 97; Redondo, 2000, pp. 92, 96; Redondo \& Zalama, 2009; Salomón, s.f., p. 141; Sebastián, 1981, p. 64), "Tocador de la Sultana" (Cavanah, 1987, p. 16. Denominación quizás referida a la antigua torre nazarí Abu-1-Hayyay que según autores como Bascle, 1872; Contreras, 2007, p. 205; Gómez-Moreno González, 1873a, p. 3; Salomón, s.f.; Velázquez de Echeverría, 1764, p. 108, fue utilizada como Mihrab u oratorio de las sultanas), "Toaletta" o "Toilette" (Gómez-Moreno Calera, 2007a, p. 11; Pavón, 1985, p. 279), "Studiolo" (Vilar, 2016, p. 195), "Mirador" (Barrios, 2016, p. 51; De Argote, 1805, p. 186; E. Rosenthal, 1988, p. 48; Gallego, 1996, p. 102; Irving, 2001, pp. 35,53; Moreno, 1993, p. 58; Salomón, s.f., pp. 141,142), "Belvedere” (Bascle, 1872; Gómez-Moreno Calera, 1985, p. 390).

${ }^{4}$ El conjunto monumental de la Alhambra fue declarado Patrimonio de la Humanidad por la UNESCO en el año 1984 con el correspondiente compromiso por parte de España de conservar y proteger el monumento.
} 
simbología y de la liturgia Cristiana Católica combinados con escenas alegóricasmitológicas y composiciones grutescas.

A pesar de que el lugar fue diseñado para Isabel de Portugal y para el propio Emperador, esta estancia junto a las salas contiguas llamadas "Habitaciones del Emperador", nunca fueron disfrutadas por la pareja imperial. Sí las ocuparían en 1624 Felipe IV (Sánchez-Montes, 2019, pp. 58-59) y su esposa Isabel de Borbón ${ }^{5}$ y más tarde, en 1730 , Felipe V e Isabel de Farnesio ${ }^{6}$.

Solo se intervino en la restauración de las estancias en las vísperas de estas visitas, por lo que el paso del tiempo y abandono por parte de la monarquía española, los agentes climatológicos, el factor humano con la mala costumbre de los viajeros románticos de incidir con rayaduras sobre la policromía de los frescos (Viñes, 2007), e incluso la explosión de un polvorín cercano a la Torre (Gómez-Moreno González, 1873b, p. 117), ocasionaron gran impacto sobre las pinturas murales. Fue a partir del siglo XX cuando se puso en valor el conjunto de la Alhambra, incluida la Torre del Tocador, y se comenzó a trabajar en su conservación ${ }^{7}$.

El Peinador de la Reina nos muestra un rico y relevante patrimonio pictórico, en el que se usan las paredes del cuarto como soportes para llenarlos de colorido con auténtica maestría. El conjunto del Peinador de la Reina -Sala de la Estufa ${ }^{8}$, Linterna ${ }^{9}$ y Mirador $^{10}$, expone una serie de pinturas al fresco con escenas navales de la Batalla de Túnez ${ }^{11}$, escenas mitológicas y alegóricas además de grutescos.

\footnotetext{
${ }^{5}$ En el Peinador de la Reina hay inscripciones pintadas al fresco con el lema "Plus Oultre (...). Cuando Felipe IV vino á esta ciudad, sustituyóse aquel lema por las iniciales de los nombres del rey y de su esposa Isabel de Borbón, y añadióse á la $F$ una $E$ pequeña, á fin de evitar se confundieran con las de los Reyes Católicos" (Gómez-Moreno González, 1873b, p. 116). A diferencia de lo que sostiene (Ramos, 1972, p. 97), asegurando que pertenecen a Felipe V e Isabel Farnesio [véase nota siguiente]. También hacen referencia a las restauraciones de 1624 para la visita de este monarca: Contreras, 2007, p. 281; E. Rosenthal, 1988, pp. 49, 157; Gómez-Moreno González, 1888, p. 126; Torres, 1931, p. 205.

${ }^{6}$ En 1729, para las vísperas de la llegada de los monarcas, se comenzó con una nueva restauración del Peinador añadiéndose las letras $F$ e $Y$ que se refieren a Felipe e Isabel en las cartelas (Lafuente, 1843, p. 162; Ramos, 1972, p. 97). Hacen referencia a la restauración llevada a cabo para la ocasión: De Argote, 1805, p. 192; E. Rosenthal, 1988, p. 49; Gallego, 1996, p. 101; Gómez-Moreno González, 1873b, p. 117; 1888, p. 145; Redondo, 2000, p. 96; Salomón, s.f., p. 141; Torres, 1931, p. 206.

${ }^{7}$ Restauraciones más destacadas las del siglo XX dirigidas por Torres Balbás (Martín, 2007; Vílchez, 1988) y las restauraciones del siglo XXI dirigidas por Juan Aguilar y Bárbara Hasbach (Aguilar \& Hasbach, 2007).

8 También conocido como "Perfumador" (Contreras, 2007, p. 277; Gómez-Moreno González, 1888; Redondo, 2000, p. 92; Torres, 1931, p. 206).

9 También llamada "Cuerpo de Luces" (Gallego, 1996, p. 109; Gómez-Moreno González, 1873a, p. 3; López, 2000, p. 117; Redondo, 2000, p. 92; Torres, 1931) o "Gabinete del Peinador" (Aguilar \& Hasbach, 2007, p. 121).

${ }_{10}$ Almansa, 2008, p. 77; Lafuente, 1843, pp. 161-164; López, 2000.

${ }^{11}$ Sobre las escenas de la Batalla de Túnez en: Aguilar \& Hasbach, 2007; Contreras, 2007; Dacos, 2007; GómezMoreno González, 1888; López, 2000.
} 
Este conjunto artístico al fresco de gusto italiano nos ofrece una visión sobre la personalidad del Emperador y un rico programa propagandístico realizado entre $1539 \mathrm{y}$ 1545 por las manos de Julio de Aquiles y Alexander Mayner, ambos discípulos de Giovanni da Udine, y este a su vez, compañero de Rafael Sanzio. Estos artistas obraron en la Alhambra por recomendación a Carlos V de su secretario Francisco de los Cobos, quien había decorado su palacio en Valladolid bajo el nuevo estilo "al romano": "valientes hombres vinieron de Italia a pintar las Casas de Cobos secretario del Emperador (...) y de allí a la casa Real de la Alhambra en Granada" (Pacheco, 1649, p. $360)$.

La logia ${ }^{12}$ o galería exterior del Peinador de la Reina, es un Mirador con vistas al barrio del Albaicín, con muros orientados al Este, Norte y Oeste, y está decorado con pinturas al fresco de grutescos sobre fondo blanco y figuras alegóricas de las Virtudes. En la composición grutesca, y entre los vanos de las ventanas que dan luz a la Linterna, cuatro templetes se muestran a lo largo de este corredor, dos en la pared Este y dos en la pared Oeste, con las figuras de Minerva, Júpiter, Abundancia y Fuego Sagrado.

A pesar del deterioro en la policromía, no dejamos de percibir la calidad técnica de estas pinturas, el gusto en el colorido, la maestría en el dibujo con clara influencia rafaelesca y el contenido simbólico, delatándonos que el Emperador y su corte contrataban un servicio de absoluta exquisitez, innovación pictórica en España y auténtico gusto artístico. Así pues, mostramos el estudio exhaustivo llevado a cabo para los templetes, realizando una reconstrucción por medio de la disciplina artística del dibujo y así crear una hipótesis visual de cómo pudieron haber sido estas escenas antes del estado actual en el que se encuentran.

\section{Minerva}

El templete de Minerva está situado en la pared Este de la galería exterior del Peinador de la Reina, entre el vano de la ventana izquierda -si nos situamos frente a la pared-y el vano de la ventana central. Se trata sin lugar a dudas de esta figura mitológica, protectora de Roma y diosa de la sabiduría, las artes y la guerra.

\footnotetext{
${ }^{12}$ Así es nombrada por algunos autores como E. Rosenthal, 1988, p. 36; López, 2000.
} 
No es casualidad que justo tras ella, al otro lado del muro, se encuentre representada en el interior de la Linterna otra figura de Minerva sobre peana con atuendo helenístico y lanza como principal atributo. De este modo podemos determinar con mayor claridad la disposición en la que se muestra Minerva de la galería exterior, en este caso semidesnuda y con la insignia de la lanza. Su parcial desnudo, con el pecho derecho al descubierto, nos confirma claramente de que se trata de una figura femenina, aunque su sexualidad queda cubierta con un paño de pureza color verde oscuro sostenido con la mano derecha, y que pasa por detrás de la espalda hasta caer por el hombro izquierdo sujeto con un nudo. Es representada descalza y el cabello rubio recogido como su similar -Minerva en el interior de la Linterna-.

Dibujada a tres cuartos, está situada en posición pedestre sobre un pedestal dorado de gran tamaño, con ligero contrapposto con la pierna izquierda avanzada con respecto a la derecha en actitud de movimiento. Se encuentra inmersa en un templete en perspectiva con formas clásicas y típicas del Renacimiento: pilares, crepidoma, entablamento y frontón triangular, y en su interior, un busto de figura masculina en colores grisáceos imitando a la piedra. En el busto, según las sombras aplicadas con el color, se intuyen dos caras: un perfil mira hacia la derecha y otro hacia la izquierda. Este juego de formas es propio de las composiciones grutescas.

El color dorado está muy presente en toda la escena. Este templete a su vez posee unas cortinas, -similares a las cortinas de las figuras de las Virtudes Cardinales y Teologales que se encuentran representadas en la galería de este Mirador-, las cuales se encuentran sostenidas por dos angelotes de perfil flanqueando el templete, con el cuerpo mirando hacia el exterior pero con la cabeza girada hacia la diosa. Estos querubines están pintados desnudos, aunque la sexualidad está tapada con una de las piernas que queda levantada y flexionada.

El templete está decorado con ornamentos vegetales de juncos, encontrados a ambos lados de dicho cenador; además, una especie de cortina con cinco divisiones aparece en la parte inferior con los colores azul, dorado y rosa, y decorados con motivos vegetales a modo de bordados, común en las composiciones grutescas renacentistas. La composición del Peinador de la Reina y la utilización de estos recursos ornamentales, está muy en conexión con las pinturas murales del palacio de Andrea Doria en Génova. 
Esta figura presenta el rostro dañado por lo que es difícil identificar sus rasgos faciales. Pese a ello, tras el estudio minucioso de las formas y elementos que la componen, se ha identificado como una representación femenina, concretamente de Minerva. Esta afirmación hay que subrayarla puesto que algunos estudios anteriores a la presente investigación habían afirmado de que se trataba de la figura del dios Neptuno ${ }^{13}$, erróneamente identificado con un tridente, basándose en el atributo con mástil que sobresale en la parte superior de la figura a la altura de la cabeza, y dividido en este punto superior en tres partes por encontrarse la capa pictórica parcialmente desconchada. Lo cierto es que, si se observa detenidamente, no es un tridente sino una lanza propia de Minerva con adorno en el extremo. El mal estado de conservación del conjunto escénico ha podido hacer pasar por desapercibida la anatomía femenina que esta figura muestra. Esta afirmación además queda sostenida como se ha dicho, por encontrarse en sintonía con Minerva del interior de la Linterna, al igual que sucede con Júpiter, el cual está representado desnudo en la galería exterior del Peinador en un templete, y a su vez pintado de nuevo tras él en el interior de la Linterna, esta vez con vestimenta.

Los autores más antiguos como Remigio Salomón afirman que "en medio de los arcos hay templetes con buena perspectiva y estatuas de Minerva, Júpiter, la Abundancia y el Fuego Sacro" (Salomón, s.f., p. 142). De la misma manera lo sostiene Simón de Argote diciendo que "en medio de los arcos hay quatro templetes con estatuas de Minerva, Júpiter, la Abundancia, y el Fuego Sacro, debaxo de dos zeletes sostenidos por esfinges; acompañados de pabellones y genios" (1805, p. 192). Quizás en épocas pasadas la policromía de las pinturas estuviera en mejor estado de conservación para poder identificar y dejar testimonio con mayor facilidad todo el conjunto de pinturas al fresco de la estancia. [Fig. 1]

\footnotetext{
${ }^{13}$ Gómez-Moreno González describe que "entre los arcos, pequeños templetes con las figuras de Júpiter, Neptuno, la Abundancia y el Fuego Sacro" (1873a, p. 8). Así mismo, y basándose en este autor, Angulo Íñiguez vuelve a reafirmar que "en unos templetes aparece de nuevo el Padre de los dioses [se refiere a Júpiter del interior de la Linterna], al par que Neptuno, la Abundancia y el Fuego Sagrado y en los ángulos las Virtudes” (Angulo, 2010, p. 42).
} 

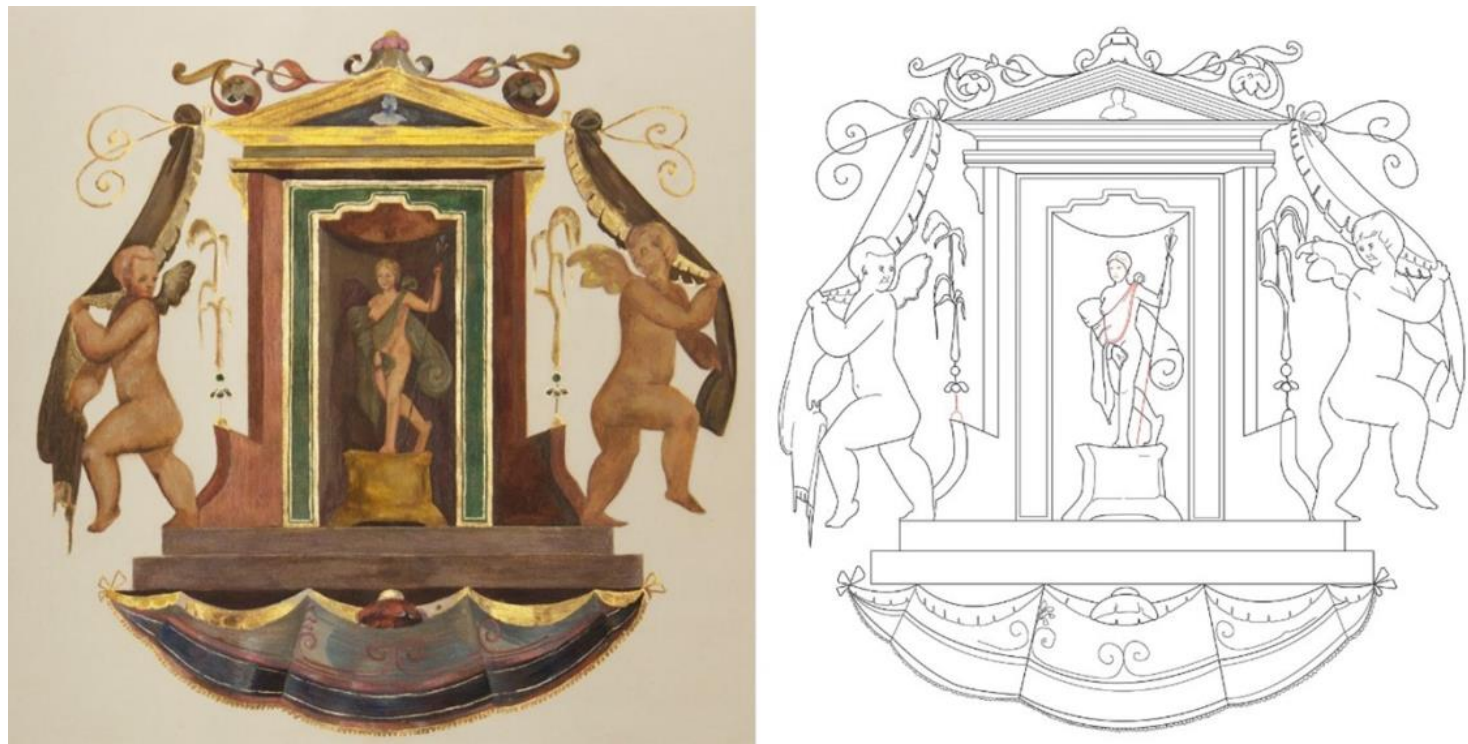

1. M. ${ }^{a}$ Isabel Puerto Fdez. Minerva. 2019. A la izquierda, técnica mixta sobre papel. A la derecha, dibujo vectorial con líneas en negro parte original y líneas en rojo parte reconstruida. Dibujado a escala 1/1 con respecto a los frescos del Peinador de la Reina.

\section{Júpiter}

En la pared Este de la galería exterior del Peinador de la Reina, nos encontramos con un segundo templete perteneciente al dios Júpiter, situado entre los vanos de las ventanas central y derecha, y en consonancia con la capilla de Minerva situada en la misma pared de este Mirador.

Tal y como sucede entre el paralelismo de Minerva de la galería exterior y Minerva de la Linterna, con Júpiter ocurre exactamente lo mismo, estando el Padre de los Dioses representado con atuendo en el interior del Peinador, mientras que en el exterior es mostrado completamente desnudo. Tan solo porta un telar color rosa asalmonado similar a los cortinajes de las figuras de Virtudes de la misma galería-, el cual es sostenido con su mano derecha y pasa por detrás de su espalda, pero sin cubrir parte alguna de su cuerpo. Sin embargo, y del mismo modo que Minerva, no se muestra la sexualidad debido al paso avanzado de la pierna derecha con respecto a la izquierda, aunque sí podemos observar el torso desnudo de un varón con musculatura marcada.

Se muestra pedestre sobre una peana dorada de gran tamaño, con pies descalzos y en posición a 3/4 con mirada hacia su izquierda. Su mano derecha se encuentra alzada con el brazo flexionado sosteniendo un atributo que nos delata de que se trata de este ser mitológico, un rayo. En cuanto al rostro, al igual que el resto de templetes pintados en 
todo el Peinador de la Reina, el de Júpiter se encuentra parcialmente rasgado, y queriendo ser representada en movimiento, una barba canosa muy poblada y hacia un lado. A pesar de mostrar un torso robusto y corpulento, las facciones son de anciano y con pelo canoso como la barba. Con estas mismas características se representa su semejante, Júpiter del reverso del muro.

Como decimos, claramente se trata de Júpiter ${ }^{14}$ identificado con la insignia del rayo en la mano, atributo adoptado de la mitología griega con Zeus. Así, el Padre de los Dioses, para el Estado Romano fue la figura de autoridad y legislador de leyes. Es importante tener una visión iconográfica a la manera carolina con significado de poder imperial para entender el concepto del conjunto de frescos representados en estas estancias.

En cuanto al templete en el que se encuentra, muestra las formas de templos clásicos con pilares, crepidoma, entablamento y frontón. Este frontón, en consonancia al de Minerva, presenta un busto en la parte central fingiendo ser una escultura en piedra con rasgos de mujer. En este caso solo posee un rostro a diferencia con el busto del templo de Minerva que posee dos.

El color dorado abunda en la policromía al igual que el color verde botella y la gama de los rojos. Hay que destacar, además, las figuras de dos angelotes desnudos flanqueando la pequeña capilla con el cuerpo hacia el exterior pero mirada girada hacia el dios, tal y como ocurre en la figura mitológica anteriormente descrita. Estos querubines sostienen cortinas que cuelgan desde el frontón el cual queda ornamentado con motivos vegetales ${ }^{15}$. El telar a modo de cortina en la parte inferior con tonos azules, rosáceos y dorados, y con división en cinco partes como ocurre en Minerva.

Es importante comentar las firmas y graffitis dejados en forma de rayaduras e improntas sobre la superficie policromada de estas estancias por viajeros románticos venidos a la Alhambra (Viñes, 2007). Esta costumbre resultó ser fatal para los frescos en estudio, ocasionando un gran deterioro en la superficie pictórica. De este modo,

\footnotetext{
${ }^{14}$ Gustave Bascle sostiene que en la pared Este "en medio de columnas y ornamentos moriscos, Minerva y Júpiter aparecen junto a las virtudes teológicas" (Bascle, 1872, p. desconocida). No obstante, tenemos que decir que los ornamentos a los que se refiere posiblemente sean a los grutescos y estos del siglo XVI de estilo italiano. Además de señalar que las figuras de las Virtudes de esta pared Este, la Templanza es Virtud Cardinal mientras que la Esperanza sí es Virtud Teologal.

15 "En medio de los arcos hay cuatro templetes con estatuas de Minerva, Júpiter, la Abundancia y el Fuego sacro: los demás adornos consisten en floreros, esfinges, animales y genios" (Lafuente, 1843, p. 162).
} 
observamos que, en el templete de Júpiter, bajo la cornisa, hay una inscripción en color negro con los siguientes caracteres "Ama (...)" y continua una frase ya borrada por el tiempo a lo largo de esta cornisa. [Fig. 2]
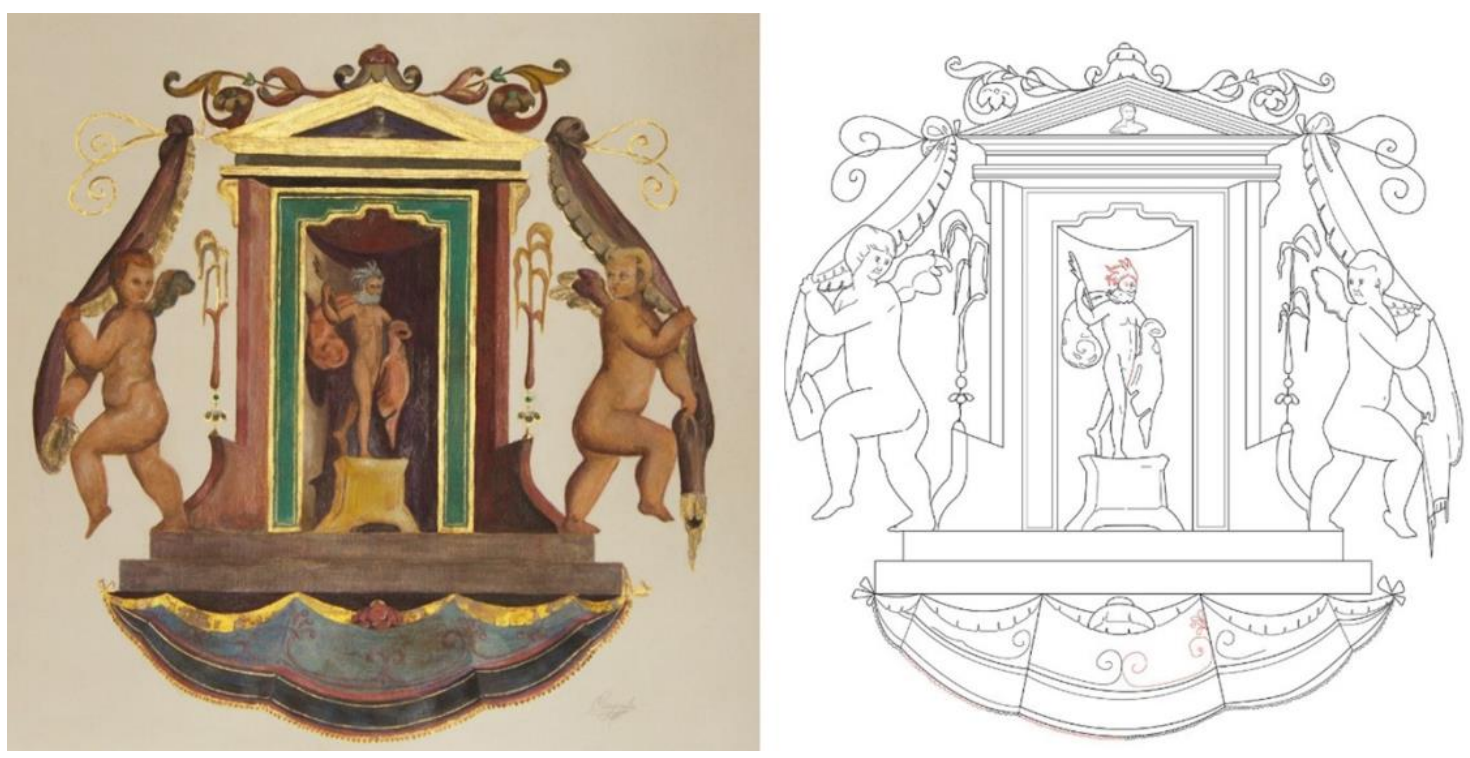

2. M. ${ }^{a}$ Isabel Puerto Fdez. Júpiter. 2019. A la izquierda, técnica mixta sobre papel. A la derecha, dibujo vectorial con líneas en negro parte original y líneas en rojo parte reconstruida. Dibujado a escala 1/1 con respecto a los frescos del Peinador de la Reina.

\begin{abstract}
Abundancia
Se trata de un templete que contiene a una figura femenina la cual varios autores a lo largo de la historia como Simón de Argote (1805, p. 192), Manuel Gómez-Moreno González $^{16}$ o Remigio Salomón (s.f., p. 142), identificaron como la alegoría a la Abundancia. Está situado en la pared Oeste de la galería exterior del Peinador de la Reina, junto al templete del Fuego Sagrado y se encuentra entre los vanos de las ventanas izquierda y central si nos situamos frente a la pared.

Tanto la representación del Fuego Sagrado como esta alegoría a la Abundancia, se encuentran en peor estado de conservación a diferencia de las figuras de la pared Este. El estado de conservación desfavorable probablemente se deba a varios factores ente los que destaquen los climatológicos, siendo esta zona y la de la pared Norte las más expuestas a las condiciones meteorológicas. También la polución causada por la

\footnotetext{
16 "En las paredes, entre los arcos de las ventanas que comunican con el interior, hay pequeñas capillas pintadas, donde se distinguen figuritas de Júpiter, Neptuno, la Abundancia y el Fuego Sacro" (1888, p. 137). Como se comentó con anterioridad, no se trata de la figura de Neptuno sino de Minerva.
} 
contaminación del siglo XXI o las incisiones sobre la policromía de visitantes a lo largo de la historia, han incentivado a ello. Sin embargo, si observamos con detenimiento, podemos intuir y descifrar la iconografía representada.

Las formas ornamentales que componen este templete muestran mejor estado que la figura protagonista, la Abundancia. No creemos que sea fruto de la casualidad que los personajes mitológicos humanizados representados en el Peinador de la Reina, tanto en la Linterna como en la galería exterior - porque en la Estufa no se representan dioses o Virtudes, al menos en las pinturas conservadas-, tengan el rostro dañado con incisiones en la policromía. Una especie de Damnatio a los dioses paganos que aquí se encuentran representados.

El color predominante es el rosa, en semejanza a la capilla del Fuego Sagrado, y está flanqueado por dos monstruos híbridos de grifos. Estos seres poseen las alas de color morado al igual que el cuerpo mientras que la cola es de color rosácea. Además de las figuras, en la composición no faltan los elementos ornamentales con motivos vegetales.

En cuanto al personaje protagonista, la Abundancia está situada sobre un pedestal en el que se observan rasgos femeninos en posición pedestre según las formas de las extremidades inferiores. Ésta se encuentra vestida, a diferencia de Minerva y Júpiter de la misma galería. Sin embargo, hay un factor de paralelismo entre todas las figuras de templetes: mientras que Minerva y Júpiter de la pared Este de la galería exterior del Mirador están desnudos, en contraposición de Minerva y Júpiter de la Linterna de la pared Este representados con vestimenta; la Abundancia se encuentra vestida en contraposición a las dos figuras mitológicas de los dos templetes de la Linterna de la pared Oeste, Diana y Baco mostrados desnudos.

El tipo de vestimenta de la Abundancia, además, está muy en consonancia con Minerva del interior de la Linterna, con túnicas helenísticas moradas ocultando los pies. De este modo, como la figura de la Abundancia se encuentra deteriorada en la parte superior, se ha optado para la reconstrucción y creación de la hipótesis visual, utilizar las formas y colores de la diosa Minerva vestida de la Linterna, con ropa grisácea en la parte superior, cabeza girada y pelo rubio recogido. Es muy típico en las pinturas renacentistas al fresco señalar el ombligo con un sombreado en la ropa ajustada a la altura del abdomen y así se ha tenido en cuenta para la reconstrucción de estas pinturas. 
También se ha colocado en su mano izquierda una cornucopia como el principal atributo de esta alegoría del que salen ramas vegetales, tal y como se aprecia en los restos de policromía verde. Mientras tanto, con la mano derecha sostiene muy probablemente un timón puesto que, aunque casi ha desaparecido este objeto, se observa una esfera en la parte inferior a la altura de los pies de la figura en color metal que posiblemente tuviera un mástil que se prolongara hasta la mano derecha de la figura.

El timón se asocia a la alegoría de la Fortuna sujeto con la mano diestra, junto con una cornucopia, sostenida con la siniestra. Quizás aquí estemos hablando de la Fortuna y no de la Abundancia, que como hemos visto, habrían pensado antiguos viajeros e historiadores. Además, tenemos que mencionar que la Abundancia, según su representación iconográfica, se muestra con una cornucopia repleta de frutos y cereales tal y como lo describe Cesare Ripa:

Con la diestra mano ha de sostener el cuerno de la abundancia, repleto de muchos y muy diversos frutos, uvas, olivas y otros semejantes. Con el brazo izquierdo ha de sujetar un haz de espigas de trigo, maíz, panizo, legumbres y otras similares, muchas de las cuales se han de ver cayendo y esparciéndose en la tierra. (Ripa, 1987, Tomo I. p. 52)

Sin embargo, junto a la figura del Peinador de la Reina, se muestran ramas vegetales de color verde, muy relacionadas con la descripción que hace Ripa sobre la diosa Fortuna:

Mujer que con la diestra sostiene una cornucopia y mientras se apoya en un timón con la siniestra una rama de Laurel. Con ello se significa que la fortuna hace triunfar a quien se le antoja, cosa que puede vesre por la rama de laurel que en la figura se pone" (Ripa, 1987, Tomo I, p. 443)

Hay una tercera deidad a la que se muestra con cornucopia, la diosa Ceres, patrona de la agricultura. Esta suele portar espigas y cereales, formas y colores que no aparecen en la escena estudiada. Del mismo modo, el significado de la diosa Ceres en estas estancias imperiales carece de sentido. Sin embargo, la alegoría a la Fortuna toma un significado muy en relación con la persona del César Carlos V, brindándole de virtud en consonancia con el resto de iconografía del Peinador de la Reina y mostrando a través de las pinturas murales un gran programa propagandístico. 
Tras el estudio, podemos llegar a la conclusión de que la protagonista de este templete sea Fortuna, sin embargo, esta hipótesis no está avalada por ningún documento histórico que lo testifique por lo que seguiremos nombrándola como Abundancia. No obstante, para la reconstrucción por medio del dibujo, se ha utilizado los atributos de cornucopia con vegetales y timón dado que son los elementos que nos sugieren los restos de policromía. [Fig. 3]
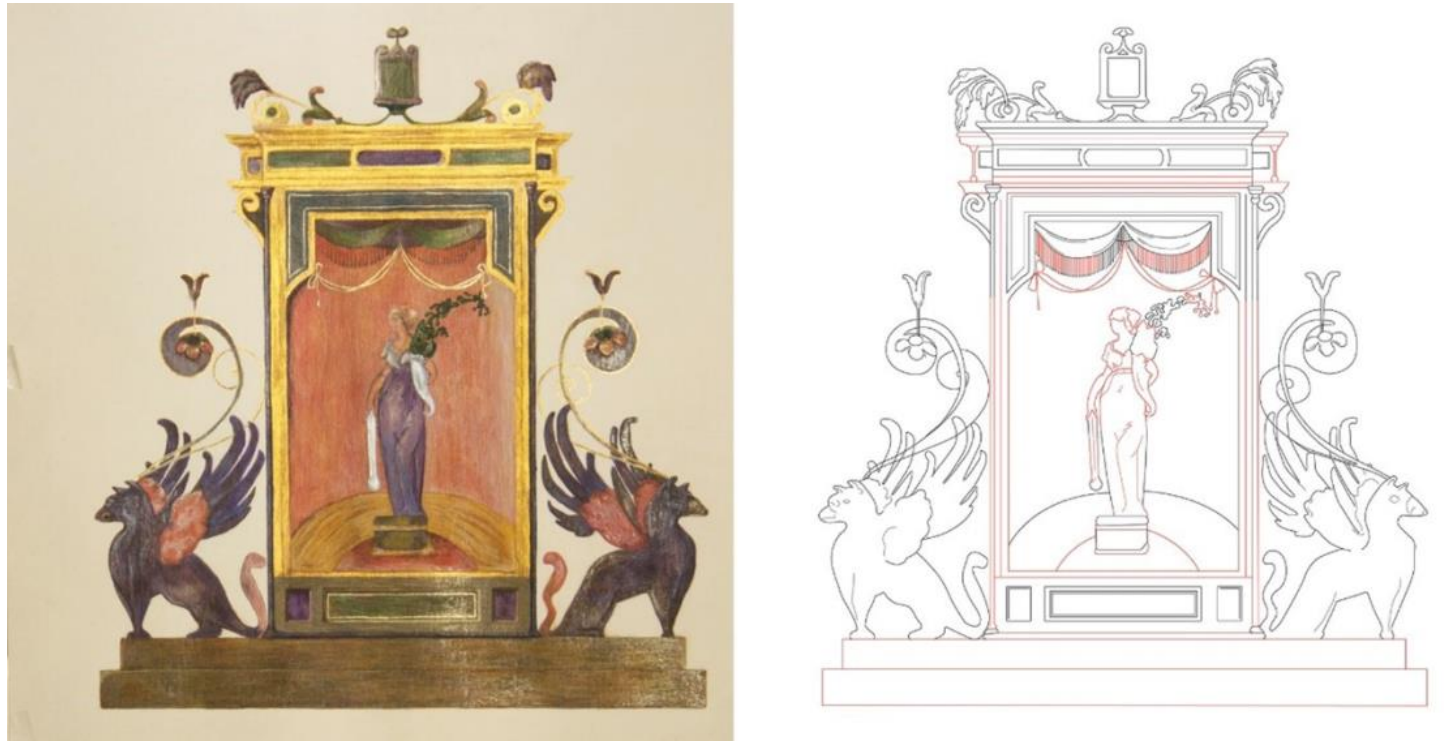

3. M. ${ }^{\mathrm{a}}$ Isabel Puerto Fdez. Abundancia. 2019. A la izquierda, técnica mixta sobre papel. A la derecha, dibujo vectorial con líneas en negro parte original y líneas en rojo parte reconstruida. Dibujado a escala $1 / 1$ con respecto a los frescos del Peinador de la Reina.

\section{Fuego sagrado ${ }^{17}$}

En la pared Oeste de la galería exterior del Peinador de la Reina, hay pintadas dos capillas: un cenador para la Abundancia tal y como se ha descrito, y un cenador para la representación de un Fuego y un Corazón Sagrado. Este segundo está situado entre los vanos de las ventanas central y derecha si nos situamos frente a la pared.

\footnotetext{
17 "Fuego Sagrado" (Angulo, 2010, p. 42; Sebastián, 1981, p. 64) o "Fuego Sacro" (De Argote, 1805, p. 192; GómezMoreno González, 1873a, p. 8; 1873b, p. 116; Lafuente, 1843, p. 162; Salomón, s.f., p. 142). El "Fuego Sagrado", representado en este templete, está vinculado a la diosa Vesta siendo sagrado en la mitología romana y con el significado de llama eterna. A pesar de ello, otros elementos representados en la misma escena cobran quizás mayor importancia simbólica: el elemento del Corazón Sagrado, más acorde con la liturgia Cristiana Católica teniendo en cuenta que estamos hablando de estancias decoradas para el Emperador del Sacro Imperio Romano Germánico, Carlos
} V. 
El Fuego, situado sobre un pedestal cilíndrico, se encuentra en la parte inferior de la escena. Este elemento está relacionado con la diosa Vesta ${ }^{18}$ como representación de la llama eterna. Para la antigua Roma, esta alegoría estaba vinculada a la fortuna del hogar y por tanto era primordial evitar su extinción. A su vez, el Fuego Sagrado ardía en un templo circular dedicado a la diosa en el Foro Romano, mostrándose en el templete del Peinador de la Reina un semicírculo en perspectiva donde se encuentra el pedestal haciendo alusión a esta forma curva del Templo de Vesta.

Pese al simbolismo mitológico romano, el Fuego Sagrado de llama eterna se ha adoptado para la representación de la iconografía cristiana en la pintura del Tocador. Sobre este Fuego encontramos un elemento que, aunque de menor tamaño, posiblemente sea de mayor importancia que la llama. Se trata de un Corazón Sagrado compuesto de dos elementos puntiagudos quizás clavos o lanzas, Cruz, ornamentos vegetales y una forma ovalada que puede significar un Corazón o el Corpus Christi. Hay que señalar que la forma ovalada representa un Ostensorio del Cuerpo de Cristo, propio de la liturgia cristiana, normalmente de color dorado.

Esta custodia es representada desde mediados del siglo XV de forma ojival y erizado de pináculos, quedando en medio una lúnula o viril para colocar en él la Hostia Sagrada y sea visible a los fieles para que la puedan adorar. En la época renacentista se construyeron en forma de templete de estilo romano y desde finales del siglo XVI se empiezan a dar en forma de sol radiante - estilo utilizado hoy en día- (Naval, 1922, p. 215).

De este modo, el viril o luneta situada en la parte central es de color ocre oscuro, a modo de cristal que deja ver el interior, la Hostia, y está circunscrito por un cerquillo dorado encerando esta forma consagrada. También aparecen una especie de flechas, concretamente dos, por detrás de este Ostensorio además de lo que puede ser una tela, quizás paño de pureza, y una Cruz latina en la parte superior de la Forma Sagrada junto a ramas vegetales. Todos estos elementos pueden representar posiblemente la pasión de Cristo, y así se puede deducir que la rama vegetal probablemente sea olivo además de algunas flores.

\footnotetext{
${ }^{18}$ Para la antigua Roma, Vesta estaba muy relacionada con la fortuna de la ciudad. De este modo, podemos crear un vínculo entre el templete del Fuego Sagrado y el templete de la Abundancia o Fortuna de la pared Oeste, de la misma forma que existe vínculo entre la diosa Minerva y el dios Júpiter, ambos representados en la pared Este.
} 
En varias pinturas al fresco sobre muros de palacios del Renacimiento, tanto españoles como italianos, encontramos representaciones de fuegos sobre peanas. Es el caso por ejemplo de dos escenas al fresco en el palacio de Villa Emo de Treviso, concretamente en el Camerino de los Grotescos, pintados por Juan Zelotti a partir de 1565 , en los que se observa una llama sobre un pedestal y dos figuras humanas a ambos lados en actitud de rezo. Del mismo modo, en el Castel de Sant'Angelo en Roma, en la sala de Pablo III, hay un fresco de un personaje masculino laureado con vestimenta romana militarizada junto a un fuego sobre pedestal ${ }^{19}$. En el palacio del Marqués del Viso en España, pintado por los hermanos Perolli y César de Bellis entre 1576 y 1587, encontramos en una de las bóvedas del patio central en la parte baja, un templete con una llama sobre una peana y en el que dos personajes híbridos con torso humano, parecen hacer ofrenda de dos animales a este fuego.

Pero sin duda, el lugar donde más escenas aparecen con esta llama sobre pedestal es en el Palacio del Infantado de Guadalajara, en concreto en la Sala de los Dioses, encontradas en las escenas del Sacrificio a la diosa Vesta; Juno y Hércules; Minerva (Marías, 1982, p. 196). En la sala de los Héroes del mismo palacio, hallamos a Mucio Escévola jurando con la mano en el fuego ante Lars Porsena (Marías, 1982, p. 194). Todas estas pinturas fueron realizadas por Rómulo Cincinato entre 1570 y 1585.

En las decoraciones grutescas de las Logias Vaticanas ejecutadas por Rafael Sanzio, Giovanni da Udine y otros artistas, se muestran en algunas pilastras un fuego sobre pedestal (Dacos, 1969; 2007, pp. 90-91).

En cuanto al cenador de tonos rosas, y a diferencia de los dos de la pared Este, no tiene frontón, aunque sí zócalos de colores morados y dos escalones en los que se encuentran dos figuras mitológicas hibridas de cabeza y alas de ave y cuerpo de león. Se trata de seres identificados como grifos, flanqueando y custodiando las figuras principales anteriormente descritas. Las alas de este ser posiblemente fuesen doradas según se intuye en los escasos restos de policromía que permanecen y porque el grifo se suele representar con las alas de este color, a diferencia del de la Abundancia que son claramente moradas. En cuanto al cuerpo de color morado, muestra musculosas patas y cola y sobre ellos, motivos vegetales a modo de ornamentación.

\footnotetext{
${ }^{19}$ Escuela Rafaelesca. Obra de 1543-1548.
} 
Se puede considerar que la ejecución de este templete, junto con el de la Abundancia, es de mayor simplicidad compositiva, además por la reducción de la gama tonal empleada con respecto a Minerva y Júpiter. Estos rasgos se dan en toda la pared Oeste, tanto en las figuras de las Virtudes como en los grutescos incluyendo estos templetes. Quizás se deba a una ejecución más apresurada por parte de los artistas en esta zona de la galería exterior, o a los repintes y malas restauraciones llevadas a cabo a lo largo de la historia. [Fig. 4]
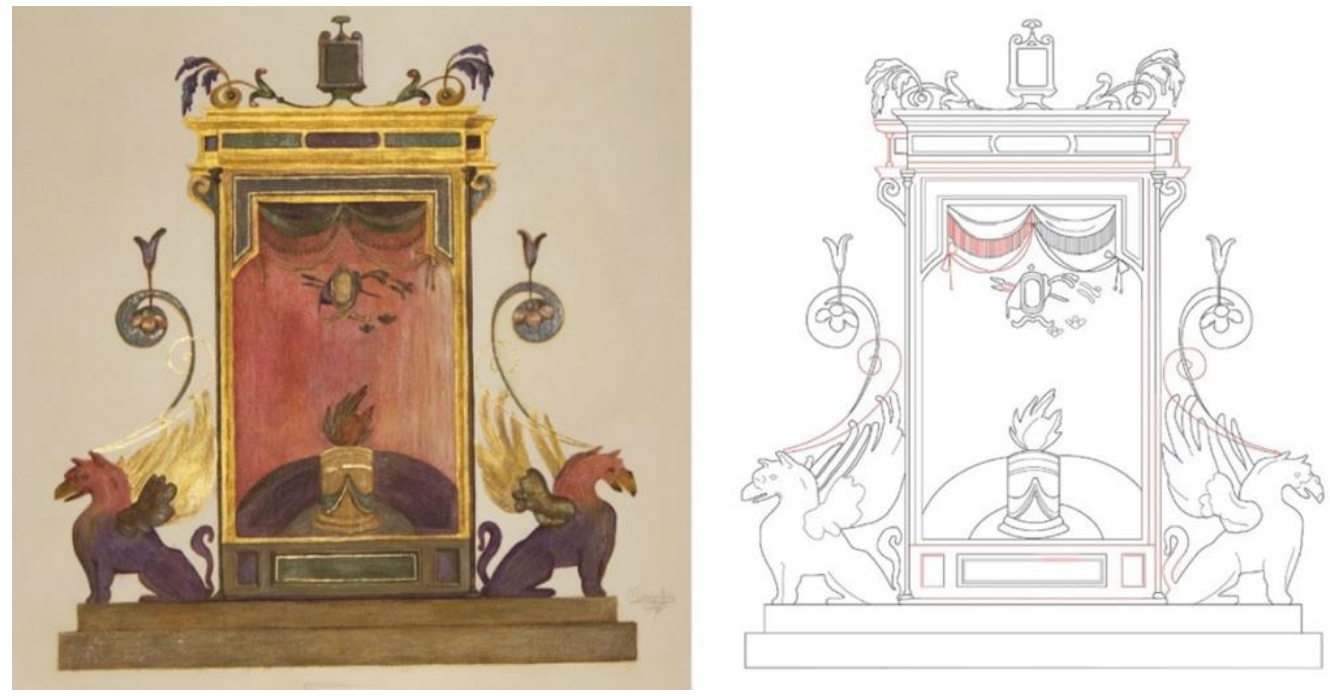

4. M. Isabel Puerto Fdez. Fuego Sagrado. 2019. A la izquierda, técnica mixta sobre papel. A la derecha, dibujo vectorial con líneas en negro parte original y líneas en rojo parte reconstruida. Dibujado a escala $1 / 1$ con respecto a los frescos del Peinador de la Reina.

\section{Hipótesis visual y conclusiones sobre los templetes}

La investigación llevada a cabo, plasma en un conjunto de nuevas obras artísticas, los templetes de la galería externa del Mirador: un primer conjunto compositivo a color, pintado con técnica mixta sobre papel, con las figuras de Minerva, Júpiter -figuras de la pared Este-, Abundancia y Fuego Sagrado -figuras de la pared Oeste-; un segundo conjunto compositivo en dibujo vectorial de línea para entender las partes reconstruidas de las figuras.

Estas pinturas al fresco en las que se utiliza el muro como soporte, están ejecutadas con una rigurosa simetría y proporción en el dibujo que caracteriza al estilo renacentista. Esta proporcionalidad nos permite entender el total de la logia, pudiendo encajar cada templete en un marco de 30 x $30 \mathrm{~cm}$ incluyendo a los angelotes y a los cortinajes inferiores 
en Minerva y Júpiter, y a los grifos para la Abundancia y Fuego Sagrado. A su vez, podemos dividir en cinco partes horizontales de $6 \mathrm{~cm}$ cada una, y cinco partes verticales con la misma medida. Estos datos nos delatan la precisión y la armonía compositiva, con una posible utilización de retícula previa al dibujo y pintura para encajar el conjunto de grutescos de cada una de las paredes del Peinador de la Reina.

Es importante destacar también que las dos capillas de la pared Este, y por otro lado las dos capillas de la pared Oeste, son idénticas en el trazo, creando una perfecta simetría axial entre las escenas de Minerva y Júpiter, y las escenas de la Abundancia y Fuego Sagrado. Esto es conseguido por los artistas Julio de Aquiles y Alexander Mayner, con la utilización de cartones preparatorios para el estudio y ejecución de estos dibujos, los cuales traspasaran a la pared (Vasari, 1998, pp. 110-111).

Están ejecutados por medio de capas de color. Por ejemplo, las figuras humanas se pintan desnudas y sobre ellas las clámides. Si observamos a Minerva que está pintada desnuda, podemos percibir restos de policromía verde oscuro sobre su epidermis además de un ligero rastro del trazo del pincel. Esto se debe a que la túnica que sostiene con uno de sus brazos, pasara por medio del torso, aunque en esta zona haya desaparecido.

Estas capas de color superpuestas también se ven en las lagunas pictóricas de estos templetes, donde la capa pictórica de los elementos del primer plano se ha borrado, quedando la capa de pintura de los objetos de segundo plano y de fondo.

Por otro lado, hay que resaltar que, si se observa con detenimiento, permanecen casi todos los colores, sobre todo los pigmentos de la gama de los rosáceos y rojos, también verdes y azules $\mathrm{y}$, sin embargo, los amarillos y dorados quedan menos conservados. Muy probablemente la utilización del oropimente, "que los griegos llamaban arsénicon, [y que] se saca en el Ponto" (Vitruvio, 1987, p. 182), para la obtención del color amarillo y dorado, sea el causante de la desaparición de este mineral debido a su incompatibilidad con otros pigmentos basados en plomo, zinc o cobre como pueden ser el cardenillo (Vitruvio, 1987, p. 186) y la azurita. La repelencia experimentada por parte del oropimente sobre otros pigmentos provoca la no adherencia a la superficie.

Además, es sabido que en algunas zonas del Peinador de la Reina se ha utilizado el dorado "al agua" para la superficie mural, técnica inadecuada para este soporte (Aguilar \& Hasbach, 2007, p. 138; Vasari, 1998, pp. 123-124). Y que "los distintos retoques 
realizados sobre las pinturas con temple oleoso o con óleo, han tenido diferentes consecuencias sobre la capa pictórica original" (Aguilar \& Hasbach, 2007, p. 138). Este hecho ha provocado que las capas aplicadas con pintura al óleo, haya ocasionado la polimerización y el levantamiento de las capas de pintura original y su caída (Aguilar \& Hasbach, 2007, p. 138).

Estos factores sean probablemente los causantes del desprendimiento de algunas zonas de la capa pictórica, ayudado además por el paso del tiempo y las condiciones meteorológicas.

En definitiva, para entender cómo pudieron haber sido los cuatro templetes de Minerva, Júpiter, Abundancia y Fuego Sagrado en su estado original y antes del deterioro parcial en la policromía, se muestra el estudio y reconstrucción por medio de la disciplina artística del dibujo, creando una hipótesis visual y así contribuir en una mayor comprensión espacial y simbólica del conjunto pictórico que conforma el Peinador de la Reina.

¿Por qué el dibujo? El dibujo es la disciplina artística primaria del que se subordinan el resto de manifestaciones artísticas. La materia del dibujo tiene la capacidad de equipararse a la escritura y al lenguaje oral como forma de expresión comunicativa universal, compresible por cualquier marco histórico, nacionalidad, condición social o edad. De este modo es quizás la forma de comunicación más pura por poseer la facultad de poder expresar tanto lo intrínseco como lo extrínseco del ser humano, de construir argumentos y de sostener conceptos de una investigación. El dibujo se emplea como medio para abordar las distintas hipótesis que manan a lo largo de la investigación. Así la obra de Arte tiene la capacidad de portar procesos cognitivos e ideas, y generar discursos con mensajes eficaces gracias a sus cualidades estéticas. [Fig. 5] 

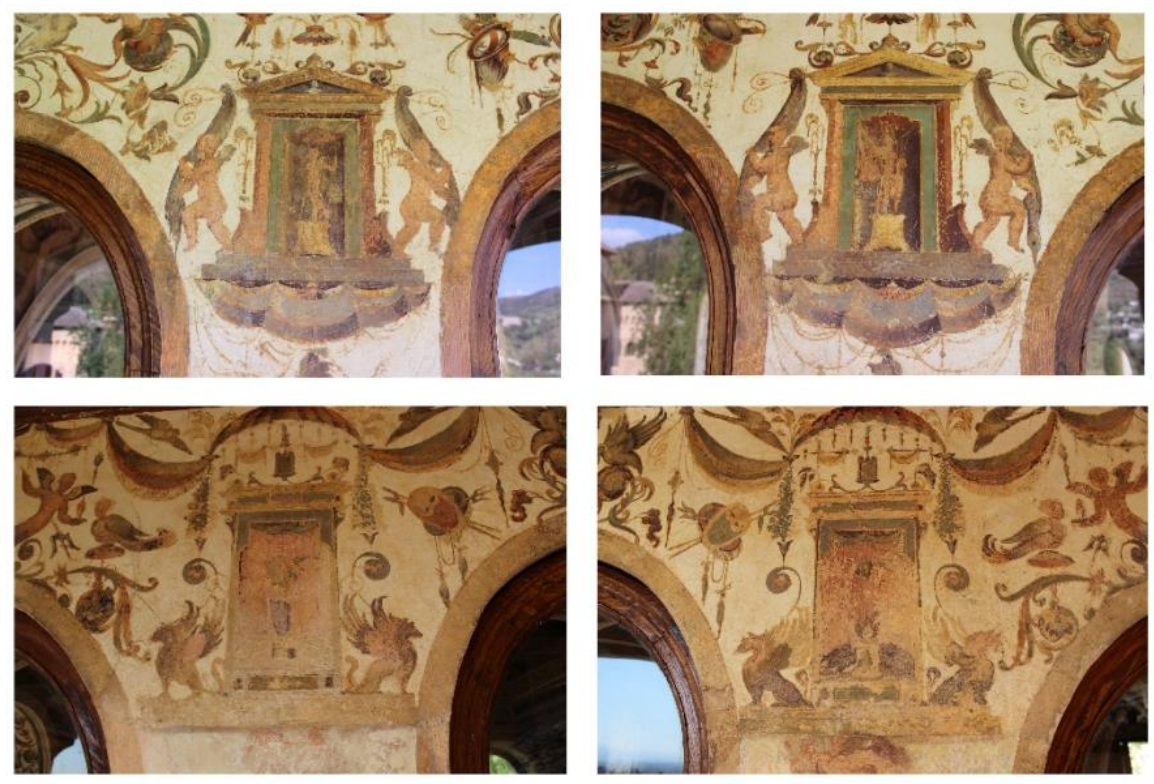

5. Julio de Aquiles y Alexander Mayner. Minerva, Júpiter, Abundancia y Fuego Sagrado. 1539-1545. Fotografía de la autora.

\section{Referencias bibliográficas}

Aguilar Gutiérrez, Juan \& Hasbach Lugo, Bárbara (2007), "Restauración y conservación del Peinador alto de la Reina". Cuadernos de la Alhambra, no 42, pp. 119-149.

Almansa Moreno, José Manuel (2008). La pintura mural del Renacimiento en el Reino de Jaén. Jaén: Instituto de estudios Giennenses.

Andros, A. C. (1860). Pen and pencil Sketches of a holiday scamper in Spain. Londres: W. Clowes and Sons.

Angulo Íñiguez, Diego (1954). Ars Hispaniae, Vol. XII: Pintura del Renacimiento. Madrid: Editorial Plus-Ultra.

Angulo Íñiguez, Diego (2010). La mitología en el arte español: del Renacimiento a Velázquez. Madrid: Real Academia de la Historia.

Barrios Rozúa, Juan Manuel (2016). Alhambra romántica: los comienzos de la Restauración arquitectónica en España. Granada: Universidad de Granada. 
Bascle de Lagreze, Gustave (1872). Pompéi: Les Catacombes: L'Alhambra: Étude a l'aide des monuments de la vie Païnne a son Déclin, de la vie Chrétienne a son aurore de la vie musulmane a son apogée. París: Typographie Firmin Dibot.

Bermúdez Pareja, Jesús (1971). Forma y color. Los grandes ciclos del arte, Vol. LV: El Palacio de Carlos V y la Alhambra Cristiana. Granada: Albaicín/Sadea Editores.

Cavanah Murphy, James (1987). Las antigüedades árabes de España: la Alhambra. Granada: Editorial Procyta S.A.

Contreras, Rafael (2007). Estudio descriptivo de los monumentos árabes de Granada, Sevilla y Córdoba, ó sea La Alhambra, el Alcázar y la Gran Mezquita de Occidente. Sevilla: Extramuros.

Dacos, Nicole (1969). Le Découverte de la Domus Aurea et la formación des Grotesques a la Renaissance. Londres: The Warburg Institute University of London.

Dacos, Nicole (2007), “<<Julio y Alejandro $>>$ Grutescos italianos y cartografía flamenca en el Peinador de la Reina”. Cuadernos de la Alhambra, no 42, pp. 81-117.

De Argote, Simón (1805). Nuevos paseos históricos, artísticos, económicos-políticos por Granada y sus contornos. Tomo II. Granada: Imprenta de D. Francisco Gómez Espinosa de los Monteros.

E. RosenthaL, Earl (1988). El Palacio de Carlos V en Granada. (Trad. Pilar Vázquez Álvarez). Madrid: Alianza Editorial.

Gallego y Burín, Antonio (1996). Granada: Guía Artística e histórica de la ciudad. Granada: Comares.

Gómez-Moreno Calera, José Manuel (1985). Valores Permanentes de la Alhambra. Granada: Universidad de Granada.

Gómez-Moreno Calera, José Manuel (2007a), “La torre de Abu-1-Hayyay o del Peinador en época nazarí: orígenes históricos y estudio arquitectónico". Cuadernos de la Alhambra, no 42, pp. 9-35. 
Gómez-Moreno Calera, José Manuel (2007b), “Transformaciones cristianas en la torre del Peinador entre los siglos XVI y XIX”. Cuadernos de la Alhambra, n 42, pp. 37-55.

Gómez-Moreno González, Manuel (1873a). Pinturas del Tocador de la Reina en la Casa Real de la Alhambra. Granada: Imp. De D. Indalecio Ventura.

Gómez-Moreno González, Manuel (1873b), “Julio y Alejandro, pintores italianos del siglo XVI, y sus obras”. El Liceo de Granada: revista quincenal de ciencias, literatura y artes. $\mathrm{n}^{\mathrm{o}} 8$, pp. 113-118.

Gómez-Moreno González, Manuel (1888), “Los pintores Julio y Alejandro y sus obras en la Casa Real de la Alhambra". Cosas granadinas de arte y arqueología. Granada: Imprenta de la Lealtad, pp. 121-147.

Gómez-Moreno Martínez, Manuel (1983). Las águilas del Renacimiento español. Madrid: Xarait ediciones.

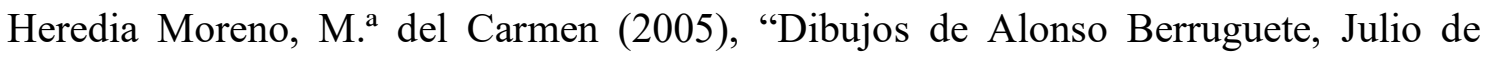
Aquilis y Andrés Melgar en la Fundación Lázaro Galdiano”. Goya, Revista de Arte, $\mathrm{n}^{\circ}$ 306, pp. 132-144.

Irving, Washington (2001). Cuentos de la Alhambra. Madrid: Espasa Calpe, S.A.

Lafuente Alcántara, Miguel (1843). El libro del viajero en Granada. Granada: imprenta y librería de Sanz.

López Torrijos, Rosa (1985). La mitología en la pintura española del siglo de Oro. Madrid: Ediciones Cátedra.

López Torrijos, Rosa (2000), "Las pinturas de la Torre de la estufa o del Peinador". En Galera Andreu, P. (ed.). Carlos V y la Alhambra (pp. 107- 129). Granada, Patronato de la Alhambra y Generalife, Consejería de Cultura.

Marías Franco, Fernando (1982), "Los frescos del Palacio del Infantado en Guadalajara: Problemas históricos e iconográficos”. Boletín de la Real Academia de Bellas Artes de San Fernando, no 55, pp. 175-216. 
Martín Cespedes, Miguel Ángel (2007), “La restauración del Peinador de la Reina realizada por Torres Balbás”. Cuadernos de la Alhambra, nº 42, pp. 57-67.

Martínez Elvira, Juan Ramón (1997), “Julio de Aquiles, el pintor italiano que vivió y murió en Úbeda". Revista Ibiut, nº 98, pp. 22-23.

Martínez Jiménez, Nuria (2019), “La trayectoria italiana de Julio de Aquiles en el Círculo de Rafael". Archivo español de arte, no 365, pp. 1-16. <Doi: 10.3989/aearte.2019.01>.

Moreno Mendoza, Arsenio (1993). Úbeda renacentista. Madrid: Electa.

Naval y Ayerve, Francisco (1922). Tratado compendioso de arqueología y bellas artes. Madrid: Viuda de Prudencio Pérez.

Pacheco, Francisco (1649). "Libro tercero de la pintura de su práctica, y de todos los modos de ejercitarla". Cap. III. De la iluminación, estofado, y pintura a fresco, y de su Antigüedad, y duración. Arte de la pintura su antigüedad y grandezas. Sevilla: Simón Faxardo, Impresor de libros, a la Cerrajeria, pp. 352-368.

Pavón Maldonado, Basilio (1985), "La torre de Abu-1-Hayyay de la Alhambra o del Peinador de la Reina”. Jornadas de Cultura Árabe e Islámica (ed.): Actas de las II Jornadas de Cultura Árabe e Islámica: (1980). Madrid: Instituto Hispano-Árabe de Cultura, pp. 429-442.

Pi Margall, Francisco (1981). Granada, Jaén, Málaga y Almería. Granada, España: Don Quijote.

Puerto Fernández, María Isabel \& Jódar Miñarro, Asunción (2020), "Estudio del patrimonio a través del dibujo: hipótesis visual sobre las imágenes de las Virtudes en el Peinador de la Reina". Revista PH, $\mathrm{n}^{\circ}$ 99, pp. 98-119. Recuperado de: https://www.iaph.es/revistaph/index.php/revistaph/article/view/4426

Ramos Torres, María Cruz (1972), “Álbum de la Alhambra: preparativos en la Alhambra ante la venida de Felipe V'. Cuadernos de la Alhambra, no 8, pp. 91-98.

Redondo Cantera, María José (2000), "La Casa Real Vieja de la Alhambra como residencia de Carlos V". En Galera Andreu, P. (ed.) Carlos V y la Alhambra. Granada: Patronato de la Alhambra y Generalife, Consejería de Cultura, pp. 53-105. 
Redondo, María José \& Zalama, Miguel Ángel (Coords.) (2009). Carlos V y las artes: promoción artística y familia Imperial. Valladolid: Universidad de Valladolid.

Ripa, Cesare (1987). Iconología. Tomo I/ Tomo II. (Trad. de Juan Barja y Yago Barja). Madrid: Akal.

Salomón, Remigio (s.f.). Guía del Viajero en Granada. Granada: Tipografía de D. Paulino V. Sabatel.

Sánchez-Montes González, Francisco (2019), "La estancia de Felipe IV en Granada en 1624: el viaje de un monarca al sur”. Andalucía en la historia, n ${ }^{\circ} 65$, pp. 56-61.

Sebastián López, Santiago (1981). Arte y humanismo. Madrid: Ediciones Cátedra.

Torres Balbás, Leopoldo (1931), "Paseos por la Alhambra: La Torre del Peinador de la Reina o de la Estufa". Archivo español de arte y arqueología, n ${ }^{\circ} 21$, Madrid, pp. 193212.

Vasari, Giorgio (1998). Las vidas de los más excelentes arquitectos, pintores y escultores italianos desde Cimabue a nuestros tiempos (Antología). (Trad. Méndez Baiges y Montijano García). Madrid: Editorial Tecnos.

Vilar Sánchez, Juan Antonio (2016). 1526 boda y luna de miel del Emperador Carlos V: la visita imperial a Andalucía y al Reino de Granada. Granada: Universidad de Granada.

Vílchez Vílchez, Carlos (1988). La Alhambra de Leopoldo Torres Balbás: (Obras de restauración y conservación. 1923-1936). Granada: Universidad de Granada.

Viñes Millet, Cristina (2007), "Viajeros en la Alhambra: el Peinador de la Reina". Cuadernos de la Alhambra, no 42, pp. 151-171.

Vitruvio Polión, Marco (1987). Los diez libros de arquitectura. (Trad. Joseph Ortiz y Sanz). Barcelona: Alta Fulla. 